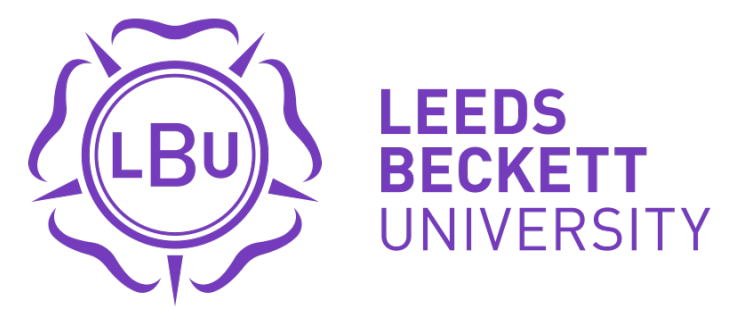

Citation:

Long, J and Bianchini, F (2018) New directions in the arts and sport? Critiquing national strategies. Sport in Society. pp. 1-20. ISSN 1743-0445 DOI: https://doi.org/10.1080/17430437.2018.1430484

Link to Leeds Beckett Repository record:

https://eprints.leedsbeckett.ac.uk/id/eprint/5228/

Document Version:

Article (Accepted Version)

This is an Accepted Manuscript of an article published by Taylor \& Francis in Sport in Society on 31 January 2018, available online: http://www.tandfonline.com/10.1080/17430437.2018.1430484

The aim of the Leeds Beckett Repository is to provide open access to our research, as required by funder policies and permitted by publishers and copyright law.

The Leeds Beckett repository holds a wide range of publications, each of which has been checked for copyright and the relevant embargo period has been applied by the Research Services team.

We operate on a standard take-down policy. If you are the author or publisher of an output and you would like it removed from the repository, please contact us and we will investigate on a case-by-case basis.

Each thesis in the repository has been cleared where necessary by the author for third party copyright. If you would like a thesis to be removed from the repository or believe there is an issue with copyright, please contact us on openaccess@leedsbeckett.ac.uk and we will investigate on a case-by-case basis. 


\section{New directions in the arts and sport? Critiquing national strategies}

Jonathan Long and Franco Bianchini

Jonathan Long is Emeritus Professor at the Institute for Sport, Physical Activity and Leisure, Leeds Beckett University (UK)

Professor Franco Bianchini is Director of the Culture, Place and Policy Institute, University of Hull (UK)

Corresponding author:

Jonathan Long,

Institute for Sport, Physical Activity and Leisure

Leeds Beckett University, Cavendish Hall

Headingley Campus, Leeds LS6 3QU

United Kingdom

Phone: 01138127565

Email: j.a.long@leedsbeckett.ac.uk

Linkedln: https://www.linkedin.com/in/jonathan-long-bb881129/

ORCiD: https://orcid.org/0000-0001-5220-1152

[Franco Bianchini

Culture, Place and Policy Institute, University of Hull, UK

Email: bianchin@aol.com

Mobile +44 7975 905144]

The research was self-funded. The Fields of Vision network was supported by the Arts and Humanities Research Council in 2016/17.

There are no conflicts of interest to declare. 


\title{
New directions in the arts and sport? Critiquing national strategies
}

\begin{abstract}
Taking as its starting point the Fields of Vision initiative's interest in promoting the potential benefits of bringing sports and arts closer together, this paper reviews how national (English) policy addresses that challenge. Four key strategic documents (the Government's Sport Strategy and its Culture White Paper as well as the strategies of Arts Council England and Sport England) are examined. That is supplemented by the views of significant individuals from this interface, including the research network funded by the Arts and Humanities Research Council (AHRC). Noting the similar social remit ascribed to sport and the arts by the Government, shortcomings in the current strategies are identified as barriers to integration. 'Play' and 'movement' are briefly discussed as integrating concepts alongside our assessment of the potential of the arts/sport nexus, in areas including aesthetic innovation, promoting health and wellbeing, and encouraging wider participation and engagement. Having challenged existing national policies the paper suggests possible future directions.
\end{abstract}

\section{Keywords}

Cultural policy, national strategies, events, participation, social benefit, integration

\section{Introduction}

It has been argued that being part of the same Government ministry (Department for Digital, Culture, Media and Sport - DCMS) is an opportunity to exploit the many potential interrelationships between sport and the arts (e.g. Long et al. 2013). Indeed, the Culture and Sport Evidence (CASE) research programme commissioned by DCMS to establish the social value and wellbeing generated by cultural and sport activities (see for example, Fujiwara et al. 2014a, 2014b; Taylor et al. 2015) might have been taken to reflect that belief. As shown by this paper, both policy areas have been set similar social challenges. Yet opportunities to maximise interactions between the two are commonly spurned despite Arts Council England (ACE) and Sport England (SE) now sharing the same London office block. Perhaps that is not surprising given the essential differences between the arts and sport identified by Mumford (this issue). Policy makers seem to be reassured by assigning things to discrete boxes.

Sport is commonly perceived as focusing on competition and physical skills, while the arts are seen as fundamentally about representations of the world, and telling stories. There are in the UK deep rooted cultural attitudes that polarise differences between the two realms. Arguably the division between sport and the arts is as deep as that between the sciences and the humanities discussed in 1959 by CP Snow in his polemic, The Two Cultures. However, we prefer to take our lead from writers like CLR James (2005; originally 1963) who challenges the dismissive scorn cultural elites often direct at sport, arguing that sport feeds 'the need to satisfy the visual artistic sense' (276/7). He mounts an eloquent case for the art of cricket in particular. 
Through the commercial paradigms applied to both sport and the arts in the context of the decline of the welfare state and of public funding, the two spheres of activity are increasingly in competition for people's leisure time and spending as well as for private sector sponsorship and advertising revenue. In some cases the two policy areas are also in competition for public funding (see, for example, the funding pressures on the arts sector created by the need to fund the London 2012 Olympic and Paralympic Games). Yet at the same time, the 2012-16 Cultural Olympiad gave fresh impetus to the arts/sport intersection, as with the imove project in Yorkshire and the Humber (Froggett, this issue). We argue that treating sport and the arts as separate worlds neglects the potential that lies in exploiting the reactions that might be fired by bringing these two fields together.

From time to time sport and the arts have been drawn closer together in Government thinking and consequent policy, though this has typically been in response to hardship and stress. For example, the Quality of Life Experiments (Department of the Environment 1977a) of the 1970s followed the oil crisis and the three-day week. Teams were deployed in four deprived areas (Dumbarton, Sunderland, Clwyd and Stoke-on-Trent) using cultural animateurs to combat deprivation by stimulating arts, sport and leisure activities generally. The authors of the resultant report noted that 'it was apparent that people do not necessarily see leisure needs and activities as divided between the 'arts' on the one hand and 'sports' on the other' (DoE 1977a, ix). However, despite documented success (DoE 1977b), the 'experiments' did not lead to comprehensive policy. Some two decades later the New Labour government's concern with social exclusion led to the establishment of a series of Policy Action Teams (PATs) to consider what policy instruments might promote social inclusion, by bringing together the actions and resources of different ministries. One of them, PAT 10 (1999), addressed the contribution of the arts and sport to social inclusion, and as such might have set a marker for the current interest in their ability to deliver social benefits. However, the subsequent implementation of the strategy tended to maintain the separation between the two fields (DCMS 2001).

Such 'moments' notwithstanding the arts and sport policy communities seem to have different ways of seeing (RIP John Berger), both the world and their particular purpose. Matters are not made easier by both being relatively low status public services with limited resources. There has been under-investment in DCMS generally, reflecting its lack of seniority as a Government ministry. At local government level these areas of discretionary activity are vulnerable at times of cuts in public spending ('austerity'). Fewer local authorities now have specialist unified leisure departments that might make more integrated provision (personal communication with Local Government Association, 29/8/17). Despite that, the examples of integration of arts and sport are generally to be found at local level. They can be viewed, for example, in the Cultural Olympiads from Athens 2004 onwards (Froggett et al. 2013) and in Le Grand Depart, organised by Welcome to Yorkshire for the Tour de France in 2014. These have featured associated cultural programmes of arts-based events. Likewise, in the private sector there are some professional sports clubs that have demonstrated a commitment to the arts, with artist-in-residence programmes; in the case of Middlesbrough FC this has been running since the early 1990s. 
Our recent investigations have examined where current public policy in England positions the Fields of Vision (FoV) interest in the potential of the relationships between sports and arts. Having identified key points emerging from policy statements we consider the similar social remit the Government ascribes to sport and arts, and suggest shortcomings of the current positions. We then turn our attention to future directions, in terms of both the initiatives proposed in Government strategies and of our own assessment.

In addition to examining four key national strategy documents, we sought the views of significant individuals at the sport-arts interface, drawn on the discussions of the research network (FoV) funded by AHRC to explore this agenda, and set that within the context of academic literature.

\section{National Strategies for Sport, the Arts and 'Culture'}

In December 2015 the government produced its Sporting Future strategy (HM Government, 2015). This was quickly followed by the Culture White Paper in March 2016. It is strange that the Government apparently does not see sport as part of 'culture'; it does include libraries, museums and heritage in its (implied) definition of culture, but not sport. Long and Strange (2009) have previously commented on the absence of sport from the collective mental map forming the cultural policy discourse. They note that in their interviews, apart from respondents with a specific sporting role, the role of sport in the city or its contribution to its cultural life was rarely considered. Those who 'did talk about sport did so in ways that highlighted its absence from debate' (69). This exclusion is not always the case; for example, the important Council of Europe study of cultural policy in European towns certainly included sport (Mennell 1976). Even Mumford (this Issue), in arguing the distinctness of sport and the arts does not suggest that sport should not be considered part of culture.

Like the Westminster government, we are somewhat constrained in our mission because, while the UK government might publish its strategy for sport and its Culture White Paper, sport and the arts are responsibilities devolved to the separate administrations in Scotland, Wales and Northern Ireland. We therefore examine here Sport England's strategy, Towards an Active Nation, published in May 2016 as a response to the Government strategy, and the Arts Council England (ACE) strategy document Great Art and Culture for Everyone (2010-20), that was updated in 2013.

"The arts are part of our national identity... The arts are also good for us. They teach our children how to rise to a challenge, nurturing the character and discipline that will help them get on in life...[They are] good for our economy... use the arts to strengthen community cohesion and give our young people new skills for life and work. Above all, the arts are fun. Learning artistic skills can lead to a lifetime of enjoyment... dreams and ambitions you have for success, the lifelong friendships you make, all these things remind us of the unique way in which the arts can excite and inspire us all... So at the heart of this strategy are three ideas that can help us make the most of this unique power of the arts in our national life. First, we will be much bolder in harnessing the potential of the arts for social good. We will change arts 
funding so it is no longer merely about people taking part, but rather how the arts can have a meaningful and measurable impact on improving people's lives... By harnessing the power of the arts for the good of our whole society, by investing in developing the talent of future stars... we can... make our country stronger for generations to come."

Most people researching in the area would not have been surprised to read the above text in the introduction to the Culture White Paper by the then prime minister, David Cameron. Except that is not what it is. It is Cameron's introduction to the Government's sport strategy with 'the arts' swapped for 'sport'. Elsewhere there are of course differences, most notably in relation to international competition (especially the Olympics with just a few months to go to Rio 2016); investment in school sport and developing talent; and 'integrity'. On the other hand, despite the strategy being about an active nation, the attention given to elite success (the second of those themes) could certainly fit the arts.

The White Paper says that culture (meaning the arts and heritage):

- should be available to everyone

- can enhance the country's international standing

- has important social benefits in terms of health, education and community cohesion

- has beneficial effects on both physical and mental health with positive physiological and psychological changes in clinical outcomes,decreasing the amount of time spent in hospital and improving mental health

- can increase the likelihood of a young person going on to further and higher education

- can contribute to social relationships and/or make communities feel safer and stronger

- improves social mobility and has a huge impact on life chances...can open doors to careers

- can play a role in tackling crime

- brings huge benefits by providing better quality of life and wellbeing within local communities

- contributes to urban regeneration.

There is clearly a considerable commonality of discourse being applied to sport and the arts. To aid the analysis word counts were conducted for each of the policy statements identified above and word clouds produced by using N-vivo (Figures 1-4). These excluded commonly occurring words not deemed to be significant in the current context.

$<<$ Figs 1-4 about here >>

\section{Great Art and Culture for Everyone}

Figure 1 represents the word cloud for the first of the strategy documents under consideration, which was produced by Arts Council England (ACE) for 2010-2020, as revised in 2013. Museums and libraries are prominent, no doubt in an attempt to secure the new arrangement whereby responsibility for them had been transferred to 
ACE. Not surprisingly, artists and excellence also feature prominently and there is much attention to structure and procedures: 'organisations', 'support', 'sector', 'investment', 'development'. An emphasis on the public is reflected in 'people', 'everyone' and 'engagement'. However, this shows the difficulty of dealing with individual words in this kind of approach. 'People' appear as workforce, consumers, creators; just as 'work' covers framework/our work as well as artists' works. From our perspective it is concerning that the document contains no mention of sport at all, though there are some references to the Cultural Olympiad as a showcase for the arts.

\section{The Culture White Paper}

The comparable word cloud for the White Paper (presented to Parliament in March 2016) similarly has a strong organisational theme, with such terms as 'funds', 'sectors', 'government', 'organisations', 'support', 'nations' and 'investment' being prominent (Figure 2). 'Heritage', 'museums', 'theatres', 'collections', 'galleries' and 'creative' all feature strongly. But this word cloud also demonstrates the need for caution in interpretation. Here, rather than referring to artworks, the appearance of 'works' tends to be about what works in terms of 'benefits', 'impacts', 'community', 'educational', 'data' and 'measures'.

Apart from the name of the Department in the headers, the only references to sport are incidental. First, sport appears alongside art when presenting findings from a British Council survey of 'factors making this country attractive', and data on volunteering from the Taking Part Survey. Second, sport and art are mentioned together in an observation that 'Ofsted inspectors take account of pupils' cultural development' (21). Later, in commending the North East Culture Partnership, DCMS notes that those contributing to the development of its Case for Culture included local sporting interests (34). Perhaps DCMS could take a leaf out of their book.

\section{Government Strategy for Sport}

Published under the title of 'Sporting Future: A new strategy for an active nation' in December 2015, the Government's strategy for sport insisted that while sports bodies were expected to increase participation, numbers alone were insufficient and greater attention needed to be given to resultant social outcomes. The message was that this necessitated wider involvement among groups known to have lower levels of participation. This in itself was hardly new having been the tenor of a much earlier strategy, Sport in the Community: The next ten years (Sports Council, 1982) and having re-surfaced from time to time in the interim.

The document contains only two mentions of the arts. The first in a section on local government: 'we want to encourage this type of partnership thinking at local level, including where local need or specific projects create natural synergies with the arts and heritage sectors' (14). That is followed by talk of directing Lottery funding at local level to bids 'when they are led by a strong coalition of [unspecified] local bodies'. The second mention of the arts occurs in a section on financial sustainability, which talks of copying the Arts Impact Fund, a partnership between ACE, Bank of America Merrill Lynch, NESTA \& the Esmee Fairbairn Foundation. It commits the Government to supporting the establishment of a Social Impact Fund 
for investment into sport, pooling public, philanthropic and commercial capital' and also to 'look at ways of enabling local communities to invest into their local sports facilities using models like community shares and crowdfunding' (56).

The word cloud in Figure 3 can be seen to reflect the concern with getting new people physically active. However, there is a tension throughout the document because, although the government is trying to set the strategy for the UK, responsibility for sport is devolved to the constituent home nations.

\section{Sport England Strategy 2016-2021}

The only reference to the arts in Towards an Active Nation (Sport England 2016, 21) observes:

Sport England will fund wider forms of walking for leisure and dance than we do today by investing in what is most appealing to our target audiences, and will deliver on the outcomes. We will not displace existing funding (e.g. from Arts Council England) and will not intervene where there is already a strong commercial offer.

The central aim is again clear (and reflected in Fig. 4): supporting new people to get physically active. To that end 'need', 'development', 'engagement' and 'community' are also prominent in Figure 4, and the document makes repeated use of 'customers'. Part of the rationale is to address the Government's health agenda. Hence the significance of those who are currently inactive, as the Government's strategy maintains that 'the biggest gains and the best value for public investment is found in addressing people who are least active' (HM Government 2015, 19)ii.

\section{Commonalities}

So given the, for us, disappointingly little reference to the arts in the sport strategies and sports in the arts and 'culture' strategies, is it possible to identify things in common?

'Activity' comes top for both sport documents; the nearest equivalent for the arts strategy is 'engagement' (also featuring strongly in both sport documents) but that is well down the list. Activity is associated with 'people', which comes next for the sport documents but is again less prominent for the arts document, where it is supplemented by 'everyone' and 'community'.

Both the Sport Strategy and the Culture White Paper incorporate quotes from ministers in related departments in an understandable attempt to get 'buy-in'. In all the documents talk of partners and partnerships abounds. This might seem no more than common sense, especially as we advocate better integration of sport and the arts, but there is some concern that it might reflect organisations divesting themselves of responsibility. It can be no surprise that, particularly after the international financial crisis that started in the late 2000s and the subsequent Government-imposed austerity measures, all the documents repeatedly return to questions of funding and investment. This accompanies an organisational theme 
addressing internal structure and dependence on other bodies. However, those envisaged relationships do not transcend the arts/sport divide.

Talk of 'development' is significant in all four documents, in terms of developing both skills and the overall economy. However, 'needs' are much more evident in the sport documents, where 'local' appears in relation to needs and opportunities. The theme of health and wellbeing is also given more attention in the sport documents than in the arts one, whereas education is apparently seen as being more significant for the arts.

The counts reflected in the word clouds can only take our analysis so far. We now shift our attention to 'social outcomes' (HM Government 2015, 8) or, in David Cameron's words, 'the impact on improving people's lives' (ibid, 6). So we now examine Cameron's challenge to sport to be 'no longer merely about how many people take part, but rather how sport can have a meaningful and measurable impact on improving people's lives... focus on the social good'. Given the fact that the Culture White Paper makes similar protestations, we examine arts policy in the same light.

\section{Social Benefit}

On her appointment as Secretary of State at DCMS in July 2016, Karen Bradley commented: 'The civil society work is an exciting addition to DCMS and fits perfectly with the department's mission to enrich lives' 'iii. This appears to reaffirm the view that 'art for art's sake' or 'sport for sport's sake' is no longer sufficient, in and of itself, to warrant public funding. In the strategy documents this is addressed in terms of: getting more people involved; enhancing wellbeing; educational contributions; and cohesion/inclusion.

\section{Engagement and participation}

The White Paper opens with a quote from Cameron (then Prime Minister): 'If you believe in publicly-funded arts and culture as I passionately do, then you must also believe in equality of access, attracting all, and welcoming all'. The ACE strategy is called Great Art and Culture for Everyone; the sport policy documents too aim to encourage those not currently participating to get involved. Jennie Price (Sport England's CEO) observes: 'We want everyone in England regardless of age, background or level of ability to feel able to engage in sport and physical activity... the balance of our investment needs to shift from people who would do this anyway to encouraging inactive people to become active' (Sport England 2016, 10).

Whereas the arts documents are oriented to consumption by audiences, sport is viewed in terms of more direct involvement, whether as physical engagement, volunteering or coaching (though in Sporting Future there is also attention to major events). All documents emphasise the importance of appealing to those not currently engaged and targeting funding to that end. For example, Sport England asserts that major grants will require applicants to involve 'a certain proportion' of inactive people. More generally, there is a commitment to at least 25 per cent spending on the inactive. Partly with that search for new participants in mind, the Government Strategy for Sport places greater emphasis on young people (5-14) and 
schools, but then gives that less coverage than to major sporting events. Moreover, school sport initiatives struggle in the face of the funding cuts required by austerity policies (Parnell et al. 2016). Such cuts damaged school sport and other opportunities for young people's engagement in sport (Phillpotts 2013). Despite some new investment, the crisis in youth engagement in sport was exacerbated by the end of the Healthy Pupils Capital Programme and of the School Sport Partnerships, and by the removal of School Sport Co-ordinators.

In the ACE document there is a recognition of the need to increase diversity, not just of practitioners and audiences/spectators, but of volunteers and workforce too.

We need to make entry routes into employment, and opportunities for people to further their careers, fairer and more accessible to all. This is as true for the leadership and governance of the sector as it is for those entering the workforce. (ACE 2013, 34)

DCMS $(2016,24)$ add: 'We will work with Arts Council England to understand the barriers that prevent people from particularly under-represented groups becoming professionals in the arts'.

The answer for arts policymakers to the issues of alienation and lack of engagement is mainly to get people to 'understand', whereas sport policymakers seem to be beginning to realise that to engage the disinterested the offering may need to change, to become more fun and informal, and less competitive (Sport England 2016).

\section{Health and Wellbeing}

These strategic documents for both sport and the arts unproblematically assert the respective contributions to physical and mental wellbeing, and therefore to cost saving through less demand on the health budget (though ACE offers no more than a brief acknowledgement of the wonder of the arts). For example, the White Paper protests the contribution, expresses a desire to know more and promises to work with ACE, the Heritage Lottery Fund and Public Health England, though not Sport England, to secure these gains. Whereas in the past the arts might have emphasised the psychological and sport the physical, there is now a growing emphasis on sport's contribution to mental wellbeing. The Cultural Commissioning Programmeiv notwithstanding, sport seems to have advanced further in demonstrating the case and establishing joint initiatives with the health sector. Sport England has a clearer idea than the arts of what they will do, e.g.:

'We will create a new, dedicated fund of $£ 120$ million to tackle inactivity over the next four years, building on the insight we gained from our Get Healthy Get Active pilots... at least 25 per cent spending on the inactive... work with Public Health England on creating suitable messages... programme of work with leading health charities to engage those with long term conditions (19). ... Many councils have taken the opportunity to integrate physical activity into public health policy as part of a wider shift from a system that treats ill-health to one that promotes wellbeing' (13). 
This theme receives much attention across the documents in terms of children's education, of the development of artistic talent or sporting ability, and of enhancing employment skills. In relation to the arts, there is a fundamental belief that (young) people have to be educated to appreciate the arts and that arts education enhances education generally. In the White Paper (p19) Nicky Morgan, then Secretary of State for Education, goes so far as to assert that 'access to cultural education is a matter of social justice'. Participation in sport too is presumed to improve rather than detract from educational performance. The Culture White Paper seems to have picked up on the idea in sport of talent development pathways, particularly for the workforce (otherwise ACE wants to make sure the 'right' talent is encouraged to develop). In a rapidly changing environment both arts and sports need their workforce to acquire new technical, business and soft skills, though with no suggestion that there may be any overlap between the two workforces. In Towards an Active Nation (p37), Sport England envisages working with CIMSPAv to support the professionalisation of the sector's workforce to create a framework of skills, establish career development pathways and provide sector staff with quality CPD to retain the most talented.

\section{Community Cohesion and Social Inclusion}

The Government's Sporting Future insists that 'sport can help build stronger communities by bringing people together, often from different backgrounds, to make them feel better about where they live, improve community links and cohesion and build social capital' (p75). Caroline Dinenage, then Minister for Women, Equalities and Family Justice, argued that 'sport has huge potential to break down barriers. It can bring people of all ages, backgrounds and cultures together, acting as a powerful social glue' (p70). Undoubtedly it can, but it also has the potential to divide (e.g. Wagg, 2002). Despite the Prime Minister's aspirations, the White Paper contains nothing more than three assertions (e.g. 'cultural participation can contribute to social relationships, community cohesion, and/or make communities feel safer and stronger' (p15). There is nothing at all in the ACE strategy on this theme.

Sport England still seems happier talking about 'community development' rather than cohesion or inclusion, even though it supposes that what is entailed in such activities is involving current non-participants in sport rather than community development per se. Thus, responsibility for inclusion is acknowledged in terms of equality of opportunity to develop talent. Volunteering, which Sport England is keen to encourage, is promoted to build social inclusion and community cohesion. 'We know that people who volunteer in sport, for example, are more likely to feel they belong in their area and people who take part in sport are likely to enjoy stronger social links with other people' (p75).

\section{Future Initiatives}

The White Paper makes a number of promises regarding interesting initiatives for the arts alone, insisting for example that the national arts and heritage Lottery funders will be brought together to deliver a 'Great Place' scheme (now running), which will 
support 'local communities' (studiously avoiding local authorities) that 'want to put culture at the heart of their local vision, supporting jobs, economic growth, education, health and wellbeing' (p9). Not only would it be easy to incorporate sport, the case for added value would be considerable. The next suggestion, to launch Heritage Action Zones, is reminiscent of the 10 Sport Action Zones (2001-6) that were set up to help combat low levels of participation in sport in communities experiencing the effects of poverty. Now, in Towards an Active Nation, Sport England is proposing to concentrate resources in 10 pilot areas.

The White Paper continues: 'Our national heritage organisations will advise communities on how they can make best use of their historic buildings, including taking ownership of them' (part of the project to divest the local state of its resources). Meanwhile, Sport England intends to set up a Community Asset Fund to build on the success of the Inspired Facilities and Protecting Playing Fields initiatives, to take on responsibility for local authority infrastructure (Sport England $2016,13)$. There is no mention of arts-sport collaboration here, although this would be in the spirit in the White Paper and could strengthen the social inclusion and public engagement impacts.

The White Paper also proposes a 'Cultural Citizens' programme to increase the number of disadvantaged children and young people having high quality cultural experiences. This initiative might be compared with Sportivate (receiving additional funding in 2017) and Sporting Champions, though those are not specifically for the disadvantaged. Again we see the different emphases on consumption in the case of the arts, and on active participation in the case of sport. There is then a commitment in the White Paper to encourage councils and owners to make empty business premises available to cultural organisations on a temporary basis, something from which sports bodies could benefit too. There is a later proposal ( $p 11)$ to establish a new virtual Commercial Academy for Culture. Anyone who has followed the attempts of governing bodies to impose financial discipline in response to off-field sagas at any number of professional football, rugby and cricket clubs in recent years might spot the potential for similar benefits in sport. Indeed, the sport documents also talk of the need for strong, visionary, more diverse leadership.

\section{Missed Opportunities?}

One of the things shared by the sport and by the arts policy documents is a separation of the worlds of the arts and sport, revealed by very weak mutual recognition and appreciation despite similar remits: to promote excellence, widen engagement and deliver social benefits. Perhaps the closest they come together is in an observation that 'the Cultural Olympiad was a special opportunity to showcase our diverse talents \& museum collections on the world stage and to make global connections' (ACE 2013, 26).

In addition, our assessment of Government strategies is that they are better at exhortation than delivery. They are anxious to claim the benefits accruing from sport and the arts, but the details of delivery have yet to be decided. Although the White Paper does at least draw on research evidence to try to substantiate the claims of benefit (e.g. through the CASE programme), there is no consideration of what it is about the arts (or sports) that will deliver such benefits. For example, while diversity 
is addressed, there is little consideration of what might meet the needs of minoritised groups, never mind what might promote community cohesion. The view seems to be that getting more people involved will automatically deliver social returns, without a critique of what is capable of achieving success. This may be partly because there are other agencies closer to the delivery of services and partly because these documents are supposedly national expressions of UK strategy while the arts and sport are devolved responsibilities to Scotland, Wales and Northern Ireland. Matters are complicated by dealing with fuzzy concepts in a categorical way. While the arts are commonly referred to in the plural, sport is more commonly in the singular. We have heterogeneous concepts with porous boundaries ('arts' and 'sport', never mind 'recreation', 'leisure', 'physical activity' or 'creative industries') being defended by passionate advocates as though they are homogeneous, singular entities.

As already mentioned, the Strategy for Sport and the Culture White Paper both feature quotes from ministers in other departments in an effort to demonstrate potential linkages. However, despite various protestations of the virtue of partnerships there is no connection to the work of other departments. For example, there is no link to the Education White Paper or to the work of the Department for Business, Innovation and Skills (BIS) or of the Department for Communities and Local Government (DCLG). These serious shortcomings reveal a mismatch between the rhetoric of joined up government and the reality. This kind of disjuncture appears elsewhere too. Like the government's Sporting Future, ACE acknowledges the role of local authorities in addressing need: 'We must take account of the differing needs of different places. We will do this in partnership with local government, the largest investor in arts and culture in England' (ACE 2013, 29). However worthy, this seems oblivious to the constraints imposed by major 'austerity' cuts in government funding to local authorities experienced particularly since 2010 .

As typified in the field of education there is a plethora of initiatives and good local examples, but no system-wide coverage. Even the 'national' network of Cultural Education Partnerships does not provide nationwide coverage. Meanwhile those in schools responsible for teaching the arts feel under threat.

\section{Discussion}

The occasions when the arts and sports have been brought closer together in policy terms, have been exceptional rather than the norm. Only one person has ever been on both the Arts Council and the Sports Council, Bernard Atha in the 1970s, and at that time there was one joint meeting of both Councils to discuss mutual interestsvi. Even then Atha's assessment was pessimistic:

There was no desire that I could discern from anyone to become more closely involved with the Arts Council and its activities because, they would never say this, but it was rather effete and un-masculine. It was the arts and so it wasn't like sport and good for the mind and spirit. The Arts Council was much less receptive to any ideas than the Sports Council... The problem with partnership is that if you're in one of those two funding bodies you're very protective of what you've got... When it comes to sport or art there's closure almost immediately. (Research interview) 
During that earlier period of economic adversity in the wake of the oil crisis consideration was given to joint provision and it was the time of the Quality of Life Experiments. An examination of the proceedings of conferences organised by the Leisure Studies Association shows that the debate was lively in academia too. Still flush with enthusiasm stemming from the 1974 reorganisation of government that gave impetus to the establishment of combined leisure services departments there was recurrent discussion of integrated organisation, policy and provision. Talk was of common challenges and converging policies to overcome political and administrative barriers (Walker, 1978). While Geraint John $(1978,5.1)$ protested that he did 'not personally believe in the 'culture' gap between Sports and Arts', Fred Inglis $(1978,2.1)$ observed that 'we busy ourselves with worrying about the divisions between sport and art and are worried also about the implications below these divisions which set art above sport and do so in such a way as to give rise to charges of elitism'. Even in our supposedly classless society four decades later it seems likely that such presumptions regarding socio-cultural positioning lie behind the twin-track policies discussed earlier. Despite calls by the New Labour governments for 'joined-up thinking' in public policy and practice (Pollitt, 2003; Long and Bramham 2006) we find ourselves rehearsing strikingly similar arguments today.

Thomson, Stokman and Torenvlied (2003) suggest a four stage model for the coordination of agendas: information sharing, proposing solutions, bargaining over the proposition, and terminating bargaining. Our research suggests that national bodies have so far only taken tentative steps into the first stage (e.g. the Taking Part survey and the CASE studies), and that the rest of the sequence remains uncharted. Our reading of the policy literature highlights four interrelated reasons that accord with our own assessment of why those responsible for national policies for sports and arts tend to be so resolute in keeping the two fields apart.

First, Bouckaert, Peters and Verhoest, (2010) note the continuing specialisation in the public sector that frustrates co-ordination. This encourages a presumption that 'others' lack the expertise to contribute to decisions and practices. Verhoest et al. (2010) suggest that those in the respective departments and agencies come to believe that they are meant to be separate and independent. Peters $(2013,572)$ argues that information sharing might be more likely with 'organisations that are perceived as more different from themselves, given that they will not be perceived as competitors within the same policy space'. This suggests a second reason: professional communities engage in turf wars to protect territory, power and autonomy (e.g. Thompson 2000; Adler and Wilkerson 2008; Pawlak 2009). It is not just a question of jobs, but also of status and perceived ability to make decisions. Atha, using military language, explains that the Arts Council and the Sports Council, and the professionals within them, 'defend entrenched positions in protection of their own'. Third, the various interest groups already represented in the decision-making are wary of new interests appearing 'at the table' for fear of having to spread what are seen as meagre resources ever thinner.

More fundamentally, Peters (2013) suggests that there are different epistemic communities. In our case the arts and sports policymakers just see things fundamentally differently, so leading to an inability to comprehend the other. 
The professional training and the expertise of individual organisations provide them with lenses through which they interpret the policy world. Even if confronted with a common problem, different organisations with different epistemic foundations may perceive the problems differently....and therefore have a limited foundation for cooperation with other organisations. (Peters 2013, 573)

Certainly this was Atha's interpretation of his tenure at the Sports Council and Arts Council. Campbell (2002) suggests that what may appear to be obstructive behaviour may be rationalised as protecting the very concepts that underlie policy in a particular area. The problem is compounded when, as appears to be the case here, there is little overlap between the networks of the professionals involved.

\section{The Arts-Sport Nexus: potential contributions}

By holding the worlds of sport and the arts separate the policy statements discussed earlier are 'missing a trick'. What would be the potential benefits of a more integrated strategy?

Crucially, sport and the arts both have magical powers to create a space of relatedness, a space of mystery and marvel. Just as the idea of competition is attracting increasing interest in the arts, so too is creativity in sports. Artists bring something different to sport and sport can present artists with inspirational ideas of physicality and movement. Members of the Fields of Vision network have identified new arts-sport hybrids that are 'interactive' and 'transformative' (Froggett in this issue). They can inspire and create a sense of magic through cultural experimentation and innovation, appealing to new audiences in the process. Such new images and experiences disrupt stereotypes of what constitutes art and sport. These stereotypes see (some) sports as being the preserve of working class men and (some) arts as appealing mainly to middle class women. Some will be encouraged by the greater opportunity for play and fun (the ludic dimension), as it is easier to play when not tied by what people think sports or arts should be. Play is central to the origins and essence of both arts and sports; it is a concept shared by theatre and cricket, music and rugby. Play is linked with risk, adventure, imagination and dreams. The arts are rediscovering their ludic origins, as shown for instance by the recent popularity of "immersive theatre", practiced in the UK by companies including Punchdrunk and dreamthinkspeak. Despite the theoretical recognition of the importance of learning through play, the underinvestment in this field is reflected in cuts in funding for playgrounds and the downgrading of playworkers' jobs.

However, a ludic approach still offers chances for both artS and sportS to attract new participants or audiences. In this increasingly commercial age the associated potential to attract new sponsors is very appealing, as are the possibilities for efficiency gains, like sharing facilities and marketing, especially at a time when cuts in public spending reduce established income streams.

As the bulk of provision is still separate, research evidence tends to consider the benefits derived from separated sport and arts provision (e.g. PAT 10, 1999; Long et al, 2002; Fujiwara et al, 2014a, b). The most clearly demonstrated benefits of any increase in engagement are found in improved mental and physical health (see, for example Taylor's presentation at one of the Fields of Vision seminars 
https://artsinsport.wordpress.com/resources/). However, the practical experience introduced at the seminars showed how sports and arts together can help to achieve social inclusion, with gains in education, employment, social cohesion and community safety as well as wellbeing. Although evolving, class remains an important factor influencing patterns of cultural consumption and participation in the UK (Savage, 2015). One of the key advantages of mixed arts-sport programming could be the broadening and mixing of audiences, by introducing unfamiliar art forms to a sport audience and vice versa.

The appropriateness of the individual measures notwithstanding, we welcome the commitment in recent strategies to trying to assess impact. Just as any arts or sport project, the kind of integrated initiatives we advocate below need to be able to demonstrate the outputs claimed for them.

\section{Possible Policies}

While there is a growing acceptance of 'Sci-Art', Sport-Art currently has little currency and, as demonstrated here, is not part of public policy. We struggle to comprehend implicit definitions of 'culture' in Government and NDPB thinking and suggest that cultural policies at all levels should clearly recognise sport's contribution to our national culture.

The government, DCMS, ACE and Sport England all urge others to join in partnerships. This would command greater credibility if ACE and Sport England were to demonstrate greater evidence of their preparedness to work collaboratively. Where 'partnerships' are established to address community need there should be an expectation that both sport and the arts will be represented and that funding will follow. Similarly, as the White Paper talked of directing Lottery funding to initiatives led by a strong coalition of local bodies, we might speculate on why this good practice is not deemed to be appropriate at national level in promoting collaboration between the arts and sports. The development of Sport-Art would benefit from taking this a step further by funding organisations beyond the established worlds of sport and the arts (e.g. youth work, community development, social work and public health) to run initiatives, as it is they who often have a better understanding of the advantages of an integrated approach.

As suggested earlier, the search for new audiences and participants featured in the strategy documents would be assisted by new forms/practices. At local level there are many arts organisations demonstrating their readiness to innovate in this way. From the world of sport comparable initiatives may sometimes take the form of 'extreme' or 'lifestyle' sports. Hitherto lifestyle sports have been little valued by policymakers, but they are slowly winning acceptance as demonstrated by Sport England's recent 'recognition' of parkour (also called free running or art deplacement). Its founders refer to it as the 'art of moving fluidly from one part of the environment to another' (McLean et al. 2006, 795). Dance, gymnastics and sports like parkour and urban exploration blur the boundaries between sport and the arts (Gilchrist and Wheaton 2011). For urban explorers, for instance, documenting the explorations through cutting edge videos and photography is as important as overcoming the physical challenges, and Gilchrist and Wheaton $(2011,117)$ identify 
projects in Brighton and Croydon where parkour receives arts funding as a form of physical theatre.

It is possible that trends like the increasing importance of women in sport (as both participants and audiences) will make the task of arts-sports collaboration easier. There is also potential in the use of 'movement' and 'the moving body' as integrating concepts. These concepts (successfully adopted by arts-sports collaboration projects like the Cultural Olympiad's imove) link sport and the arts with the increasingly important strategic objective of promoting physical and mental health and wellbeing by combating sedentary lifestyles at all ages and encouraging active ageing to counteract dementia and other conditions.

Proposals for co-location might encourage dialogue if extended to bring together sport and arts organisations, in a return to the joint provision that was briefly on the agenda in the 1970s. Equally the community asset transfers being precipitated by the squeeze on local government finances may also trigger combined Sport-Art initiatives as community trusts recognise the need to broaden their newly acquired facilities' appeal to make them financially sustainable. For example, to keep afloat, Bramley Baths, a community enterprise in Leeds, runs aqua-ballet sessions, hosts film shows and has had a string quartet playing in the swimming pool.

Such a shift in emphasis will take time to evolve, suggesting yet again the importance of planning for the longer term, not just short ('demonstration') initiatives. Experiments are all well and good, but it takes a lot to turn round oil tankers, especially if they are fully laden with the cultural baggage of established practice.

\section{Conclusions}

We examined national policy statements in the hope that they pointed the way to future integrated practices, only to find that they lagged behind what is happening on the ground. If the sport sector is showing more attention to arts policy than the arts sector is showing to sport policy, it is only marginal.

It is not just the four strategy documents discussed here that demonstrate a lack of integration of sport and the arts. A wider reading of the policy literature and party manifestoes for the 2017 UK General Election suggests the same. However, at other levels, integration can be evidenced in more than just integration of cultural forms. For example, there may be integration of provision, as when community projects do not offer only sports or only arts, but can provide either as appropriate in the interest of securing community development. Equally sport and the arts may be combined in an expression of cultural identity, whether by a socio-political elite (Henley, Glyndebourne, Covent Garden, Ascot...) or by a marginalised social group. In the case of the Leeds African Caribbean community this might be through Carnival, the Caribbean Cricket Club, Fforde Grene football, reggae and ska, even dominoes at the West Indian Centre. Equivalents might also be identified for LGBT communities and other groups keen to establish a sense of shared identity. Such processes do not constitute policy, but the seeds of new policies may lie outside established forums. This is why policies concerned with lifestyle, youth and public health may be more accommodating to combined arts/sport initiatives than the entrenched interests of traditional arts or sports policy communities. 
Despite sharing the same building Sport England and Arts Council England seem determined to protect their separateness while at local level there are some keen to bridge across established boundaries, even though integrated local authority leisure departments are no longer the norm.

To date we have found little evidence of looking to international experience to learn what might be most productive in creative and social terms. We can see a role for the Fields of Vision network here and suggest there may be potential in the developing concept of culture urbaine in France. This encompasses art forms like graffiti, rap, slam poetry, hip hop, beatbox, urban dance (including breakdancing), photography and video, as well as sports represented by the French League of Urban Sports, founded in 2009: parkour, skateboarding, BMX cycling, street basketball, street football, street golf, street surfing, urbanball, quick soccer and street fishing. We are aware that similar projects may be found on the ground in the UK, but since the late 1990s different French governments have recognised the potential of arts-sport collaboration within the framework of the concept of 'urban cultures', especially as a response to the problem of youth unemployment and marginalisation, and to the risk of radicalisation of young Muslims in the suburbs of French cities including Paris, Lille, Lyon and Marseilles. France now has a National Urban Cultures Observatory, several festivals cutting across the arts-sport divide, and institutions like the Centre Eurorégional des Culture Urbaines in Lille, inspired by an idea of Lille-born rapper Axiom and supported by Lille City Council.

The way in which differences between 'sport' and 'the arts' are reinforced by the strategies we have examined does not bode well for efforts to integrate the two. One of the problems we have noted is the paucity of 'intercultural mediators' (Bernard Atha being a rare example), who can encourage dialogue, encounter and exchange between the two policy communities. Like other forms of intercultural exchange and crossover (for example, in music, gastronomy, fashion and design) arts-sport collaboration could encourage aesthetic, conceptual, organisational and product innovation. It could form part of a bold rethinking of cultural policy, comprising mixed arts-sport public spaces and institutions. An uphill battle awaits in bridging the organisational chasm between sports and arts, yet that also offers scope for making an impact in an underdeveloped area of work. If sport and the arts are understood at policy level as alien concepts the challenge for those like us who want to bring them together is to reframe the issues involved. This can happen through further research on the benefits of collaboration and integration and through pilot projects - e.g. twinning schemes between museums and sports clubs, or experimental sport-arts centres.

The French experience and individual local initiatives in the UK suggest that perhaps the best chance of achieving greater integration lies somewhere beyond the rigidities of established arts and sports policy communities: in health, youth work, community development or other social policy arenas.

\section{References}


Adler, E.S. and J.D. Wilkerson. 2008. Intended Consequences: Jurisdictional Reform and Issue Control in the US House of Representatives. Legislative Studies Quarterly 33(1), 85-112.

Arts Council England. 2013. Great Art and Culture for Everyone, 2010 -2020: 10year Strategic Framework. 2nd ed. London: ACE.

Bouckaert, G, B.G. Peters and K. Verhoest. 2010. Coordination of public sector organizations: Shifting patterns of public management. Basingstoke: Palgrave.

Campbell, J. 2002. Ideas, politics and public policy. Annual Review of Sociology 28(1), 21-38.

Culture White Paper, The, 2016 (Cm. 9218) London: DCMS.

Department for Culture, Media and Sport. 2001. Building on PAT 10. Progress Report on Social Inclusion. London: DCMS.

Department of the Environment. 1977a. Leisure and the Quality of Life: a report on four local experiments. Volume 1. London, HMSO.

Department of the Environment. 1977b. Leisure and the Quality of Life: a report on four local experiments. Volume 2, Research Papers. London, HMSO.

Department of Health. 2011. Start Active, Stay Active: A report on physical activity for health from the four home countries' Chief Medical Officers. London: Department of Health.

Froggett, L., J. Manley, A. Roy and S. Hacking. 2013. An Evaluation of imove: Final Report. Preston: UCLAN.

Fujiwara, D., L. Kudrna, and P. Dolan. 2014a. Quantifying the Social Impacts of Culture and Sport. London: DCMS.

https://www.gov.uk/government/uploads/system/uploads/attachment_data/file/30489 6/Quantifying_the_Social_Impacts_of_Culture_and_Sport.pdf

Fujiwara, D., L. Kudrna, and P. Dolan. 2014b. Quantifying and Valuing the Wellbeing Impacts of Culture and Sport. London: DCMS.

https://www.gov.uk/government/uploads/system/uploads/attachment_data/file/30489

9/Quantifying_and_valuing_the_wellbeing_impacts_of_sport_and_culture.pdf

Gilchrist, P. and B. Wheaton. 2011. Lifestyle sport, public policy and youth engagement: examining the emergence of parkour. International Journal of Sport Policy and Politics 3(1): 109-131. doi: 10.1080/19406940.2010.547866

HM Government. 2015. Sporting Future: A New Strategy for an Active Nation. London: Cabinet Office. 
Inglis, F. 1978. The Imagery of power: Sporting institutions and sporting individuals. In, Community Leisure and Culture: Arts and Sports Provision, edited by B. Rees and S. Parker, 2.1-2.4. Eastbourne: Leisure Studies Association.

James, CLR. 2005. Beyond a Boundary. London: Yellow Jersey Press.

John, G. 1978. Sports/Arts Building Design. In, Community Leisure and Culture: Arts and Sports Provision, edited by B. Rees and S. Parker, 5.1-5.6. Eastbourne: Leisure Studies Association.

Long, J. and P. Bramham. 2006. Joining-up Policy Discourses and Fragmented Practices: the precarious contribution of cultural projects to social inclusion? Policy and Politics 34 (1), 133-151.

Long, J. and I. Strange. 2009. Mission or Pragmatism? Cultural Policy in Leeds Since 2000. In Sport, Leisure and Culture in the Postmodern City, edited by P. Bramham \& S. Wagg, 63-82. Aldershot: Ashgate.

Long, J., J. Parry, D. Sandle, and K. Spracklen. 2013. Introduction. In Fields of Vision: The Arts in Sport, edited by D. Sandle, J. Long, J. Parry and K. Spracklen, vix. Eastbourne: Leisure Studies Association.

Long, J., M. Welch, P. Bramham, K. Hylton, J. Butterfield and E. Lloyd. 2002. Count Me In: the dimensions of social inclusion through culture and sport. Report to the Department for Culture Media and Sport.

http://eprints.leedsbeckett.ac.uk/638/

McLean, C.R., S. Houshian, and J. Pike. 2006. Paediatric fractures sustained in parkour (free running). Injury 37(8), 795-797.

Mennell, S. 1976. Cultural Policy in Towns. Strasbourg: Council of Europe.

Parnell, D., K. Spracklen and P. Millward. 2017. Sport management issues in an era of austerity. European Sport Management Quarterly 17(1), 67-74.

Pawlak, P. 2009. The External Dimension of the Area of Freedom, Security and Justice: Hijacker or Hostage of Cross-pillarization? Journal of European Integration. 31(1), p25-44. DOI: 10.1080/07036330802503825

Peters, B.G. 2013. Toward policy coordination: alternatives to hierarchy. Policy and Politics 41(4), 569-84. doi: 10.1332/030557312X655792

Phillpots, L. 2013. An analysis of the policy process for physical education and school sport: the rise and demise of school sport partnerships. International Journal of Sport Policy 5(2), 193-211.

Policy Action Team 10. 1999. Arts and Sport: a report to the Social Exclusion Unit. London: Department for Culture Media and Sport. 
Pollitt, C. 2003. Joined-up Government: a Survey. Political Studies Review 1(1) 3449. doi:10.1111/1478-9299.00004

Savage, M. 2015. Social Class in the $21^{\text {st }}$ Century. London: Pelican.

Snow, C.P. 1959. The Two Cultures. London: Cambridge University Press.

Sport England. 2016. Towards an Active Nation. Strategy 2016-2021. London: Sport England.

Sports Council. 1982. Sport in the Community: the next ten years. London: The Sports Council.

Taylor, P., Davies, L., Wells, P., Gilbertson, J. and Tayleur, W. 2015. A Review of the Social Impacts of Culture and Sport. London: DCMS.

https://www.gov.uk/government/uploads/system/uploads/attachment_data/file/41627 9/A_review_of_the_Social_Impacts_of_Culture_and_Sport.pdf

Thompson, J.D. 2000. Organisations in action: Social sciences basis of administrative theory. New Brunswick, NJ: Transaction Press.

Thomson, R., F. Stokman and R. Torenvlied. 2003. Models of collective decisionmaking: Introduction. Rationality and Society 15(1), 5-14.

Verhoest, K., P. Roness, B. Verschuere, K. Rubecksen and M. MacCarthaigh. 2010. Autonomy and Control of State Agencies. Basingstoke: Macmillan.

Wagg, S. (ed.) 2002. British Football and Social Exclusion. London: Frank Cass

Walker, G. 1978. European Problems of Cultural and Sports Provision. In, Community Leisure and Culture: Arts and Sports Provision, edited by B. Rees and S. Parker, 3.1-3.11. Eastbourne: Leisure Studies Association. 
Figure 1: Great Art and Culture for Everyone - Word Cloud

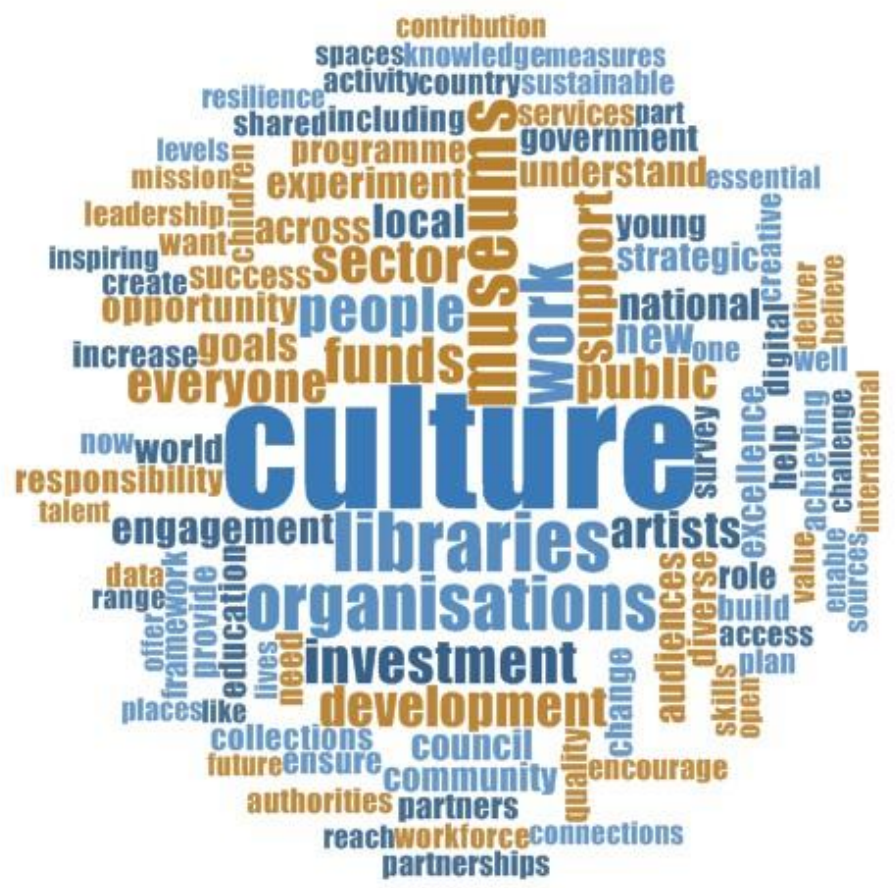


Figure 2: The Culture White Paper - Word Cloud

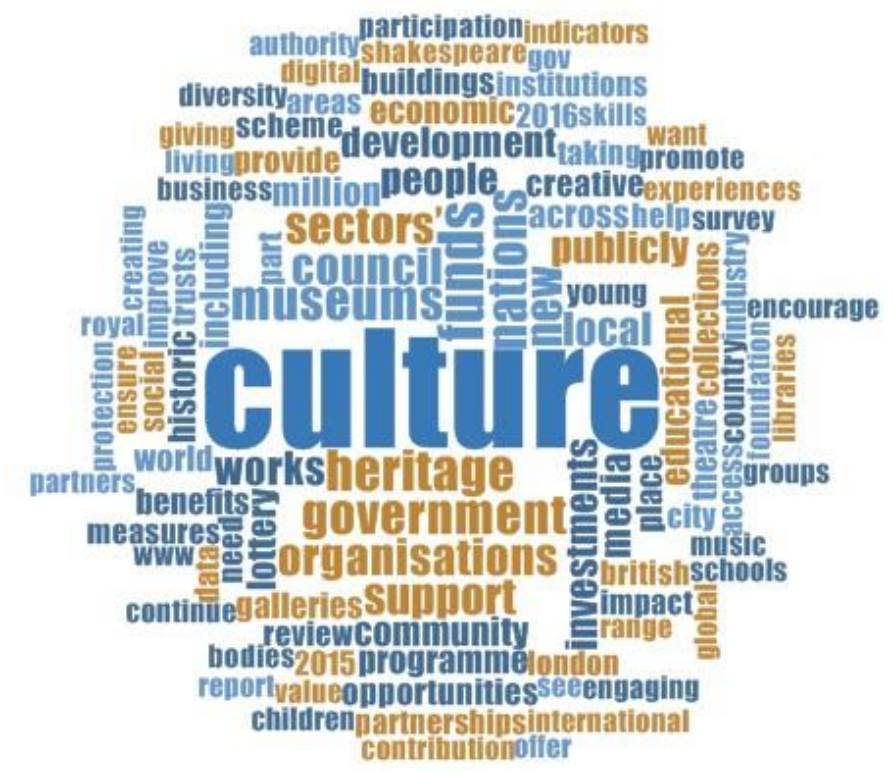


Figure 3: Sporting Future - Word Cloud

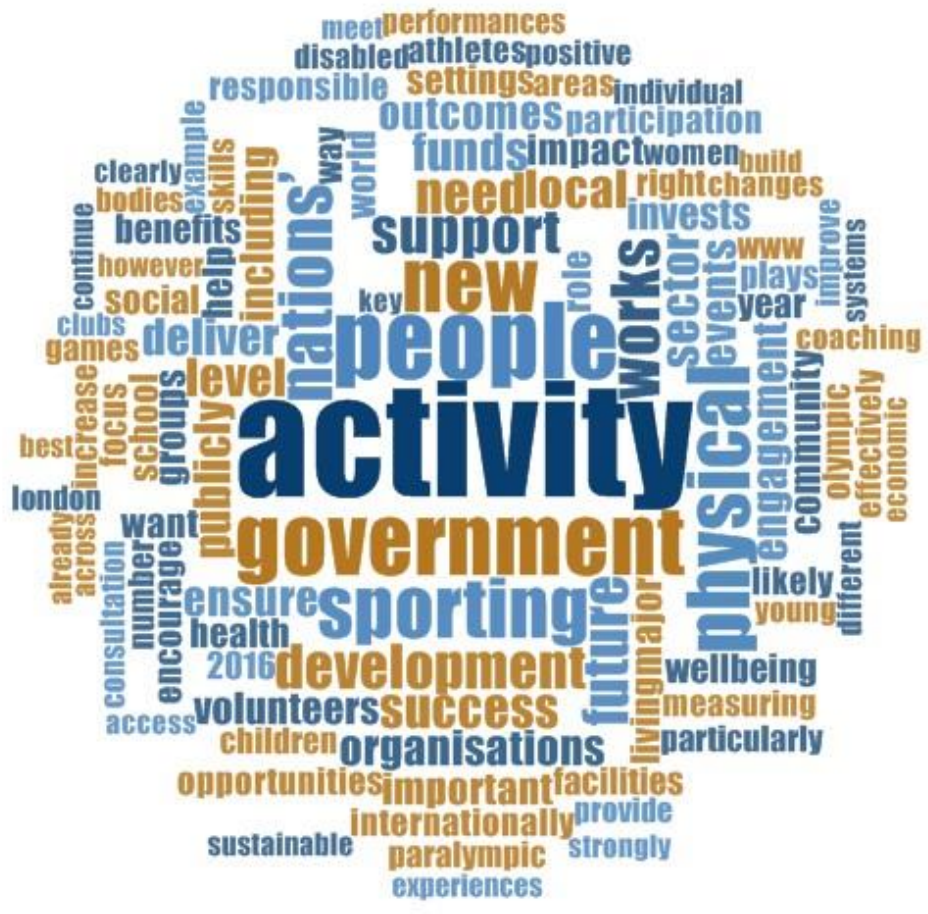


Figure 4: Sport England: Towards an Active Nation - Word Cloud

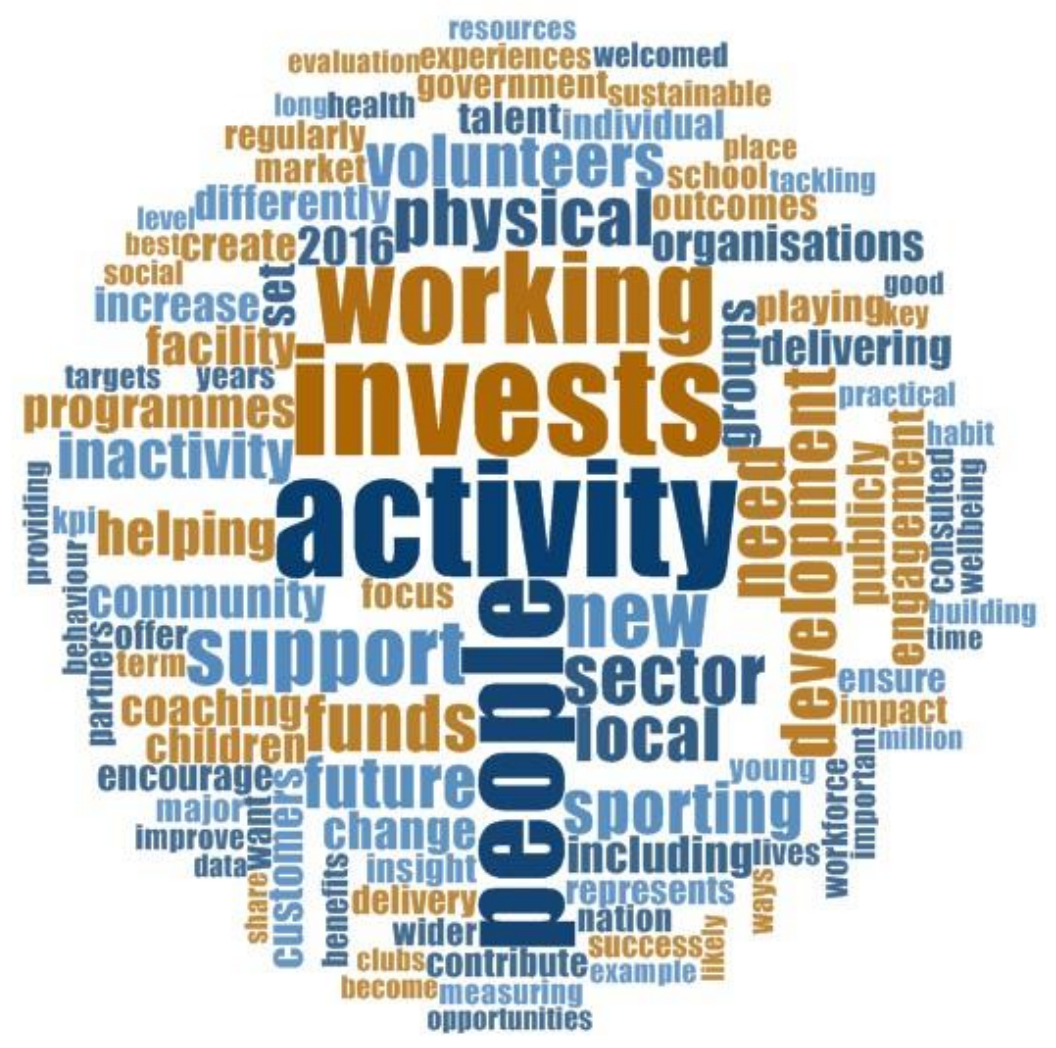




\footnotetext{
' https://artsinsport.wordpress.com/

ii This echoes the Chief Medical Officer (DH 2011, 17): 'from a public health perspective, helping people to move from inactivity to low or moderate activity will produce the greatest benefit'.

iii https://www.gov.uk/government/news/new-ministerial-team-at-dcms-confirmed (last accessed 20 April 2017)

iv The National Council for Voluntary Organisations leads a consortium using funding from ACE to help improve the interaction between cultural organisations and public sector commissioners to develop greater awareness of the potential for cultural organisations to deliver social benefits.

${ }^{v}$ According to the web site of the Chartered Institute for the Management of Sport and Physical Activity, it provides leadership, support and empowerment for professionals working in sport and physical activity, and a single voice for the sector: https://www.cimspa.co.uk/

vi We have been unable to identify record of a more recent equivalent.
} 